\title{
EL PINTOR MIGUEL CABRERA Y LA INFLUENCIA DE RUBENS
}

\section{Por Santiago Sebastidn}

$Y_{a}$ el lector conoce sobradamente la influencia que ejercieron los modelos grabados europeos en el medio hispanoamericano. La Nueva España no podía dejar de escapar a esta corriente y ya desde el siglo xvi esta influencia va en aumento tanto en lienzos como en decoraciones murales. El autor de este breve trabajo ha podido identificar algunos de los elementos decorativos de la escalera del convento de Actopan e incluso el modelo de la Virgen del Perdón, obra de Pereyns. No es esta la ocasión de pasar revista a todas las identificaciones de fuentes grabadas de obras hispanoamericanas. Por el momento destacaré la influencia de los tipos de Rubens, ya presente en México desde el siglo xvu (Juárez, Villalpando, etcétera); ya en otras ocasiones he publicado notas sobre la influencia rubeniana, ${ }^{1}$ ello explica que al visitar el Museo de América reparase en una pintura de Miguel Cabrera que responde en líneas generales al conocido modelo de Rubens. Espero un trabajo de la investigadora norteamericana Úrsula Trenta, detectando mís influencias de Rubens, que está próximo a aparecer.

El lienzo de "La Adoración de los Reyes Magos" del Museo de América de Madrid, sala $3 \mathrm{C}$, está firmado (M. Cabrera pinxitl) y mide 1.28 por 1.04 metros. Sigue en líneas generales la obra de Rubens que reproducimos y que fue grabada por Schelte de Bolswert.2 Varfa fundamentalmente la posición de la Virgen, la del Niño Jesús y la del rey que se acerca a ofrecerle oro, también Cabrera cambió ligeramente el fondo arquitectónico, rompiendo el arco de medio punto por donde penetra la comitiva armada de los Reyes, para dejarnos el cielo abierto, aunque aún mantuvo en el edificio frontero la cornisa de la imposta del aroo. Añadió un niño a la derecha que no figura en el original. En fin, uno de tantos arreglos de los que hicieron los pintores coloniales.

Sirva esta oportunidad para dar noticia de otras pinturas de Miguel Cabrera existentes en el mismo Museo de América, en la sala 3C. Por compra adquirió este museo madrileño en 1948 un "San José con el Niño Jesús", en cobre, que mide 0.57 por 0.43 metros y está firmado

1S. Sebastian, La influencia de Rubens en la Nueva Granada, Academia te Historia del Valle del Cauca. Cali 1966.

2 M. Roses, L'oeutre de P.P. Rubens. t, Hmina 55. 
(Mic. Cabrera feci) . No podía faltar una "Virgen de Guadalupe", lienzo que mide 1.78 por 0.98 y está firmado (Michl. Cabrera pinxit Mexici. Anno Domini 1763). Se atribuye a prolífico pintor barroco mexicano una "Adoración de Ios Pastores", que mide 1.28 por 1.04 metros; tanto éste como el de la "Adoración de los Reyes" constituyen un depósito del señor Suárez Fiol.

Incluso existe una copia del siglo xvin del famoso retrato de Sor Juana Inés de la Cruz, que hiciera Cabrera en 1750 y que se guarda en el Museo Nacional de México; la copia fue realizada por el pintor Andrés Islas en 1772, artista catalogado por Toussaint, ${ }^{3}$ pero dando como existente el lienzo en el Museo Arqueológico de Toledo, sin embargo sabemos que con posterioridad la Dirección General de Bellas Artes lo depositó en el Museo de América. Juzgo que vale la pena reproducir la leyenda que lleva por tratarse de la ilustre escritora novohispana:

De la M. Juana Inés de la Cruz; Muger admirable por las Ciencias, Facultades y Artes y varios idiomas que poseyó perfectamente: Cétebre y famosa en el Coro de los mayores y excelentes poestas latinos y castellanos en el Orbe, a quien con razón se le da el epítheto de Musa Décima por su singular y egregio Numen: Fénix de la América; glorioso desempeño de su sexo: honra de la Nación de este nuevo Mundo; y argumento de las admiraciones y elogios del Antiguo; Nació a las once de la noche del día doze de Noviembre de el año 1651. En una pieza llamada la Celda de la Hazienda de Labor nombrada Sn. Miguel Nepantla, Jurisdicción de Chimalhuacán, Prova de Chalco (distante 13 leguas de México). Fueron sus padres el Capit ${ }^{n}$ D. Pedro Asuaje y Vargas Machuca y $D^{\mathfrak{a}}$ Isabel Ramírez, vecinos de la citada jurisdicción. En el siglo fue conocida por $\mathrm{D}^{\mathrm{a}}$ Juana Ramírez (por q. assi firmaba). Tomó el Havito de Religiosa en el Convto del Eximio Dr. de la Iglesia San Gerónimo de esta ciud. de Mexco el 24 de Febo de 1669 as a los 17 de su edad; haviendo antes florecido en su Virgnl. estado en el RL Palaco dls EXcmos. Señor Virreyes de esta Nueva España, Marqueses de Mancera sus Protectores; Recibió el velo de profesora gobernándola el $11 \mathrm{tm}^{\circ}$ y Excmo ${ }^{\circ}$ Sr. Dr. Fr. Payo Enríquez de Rivera, arzobispo Virrey de ellas, dia de $e^{8}$ Mathias a 24 de febrero de 669. Exercitó con aclamación continuas demostraciones de su gran Sabiduría y el empleo de Contadora de su Convt ${ }^{\circ}$ por espacio de 9 años y desempeñándolo con varias heroicas operaciones; y las de su gobierno en el Archivo. Escrivió elevadisimos Poemas Latinos, Castellanos, Mexicanos y en otros ydiomas como consta de sus obras recogidas e. los 3 Tomos q. corren impresos, bien que no todos se lograron por su modesto descuido (de que es una

3 M. Toussaint, Pintura colonial en México. 174. México 1965. 
DOI: http://dx.doi.org/10.22201/iie.18703062e.1974.43.991

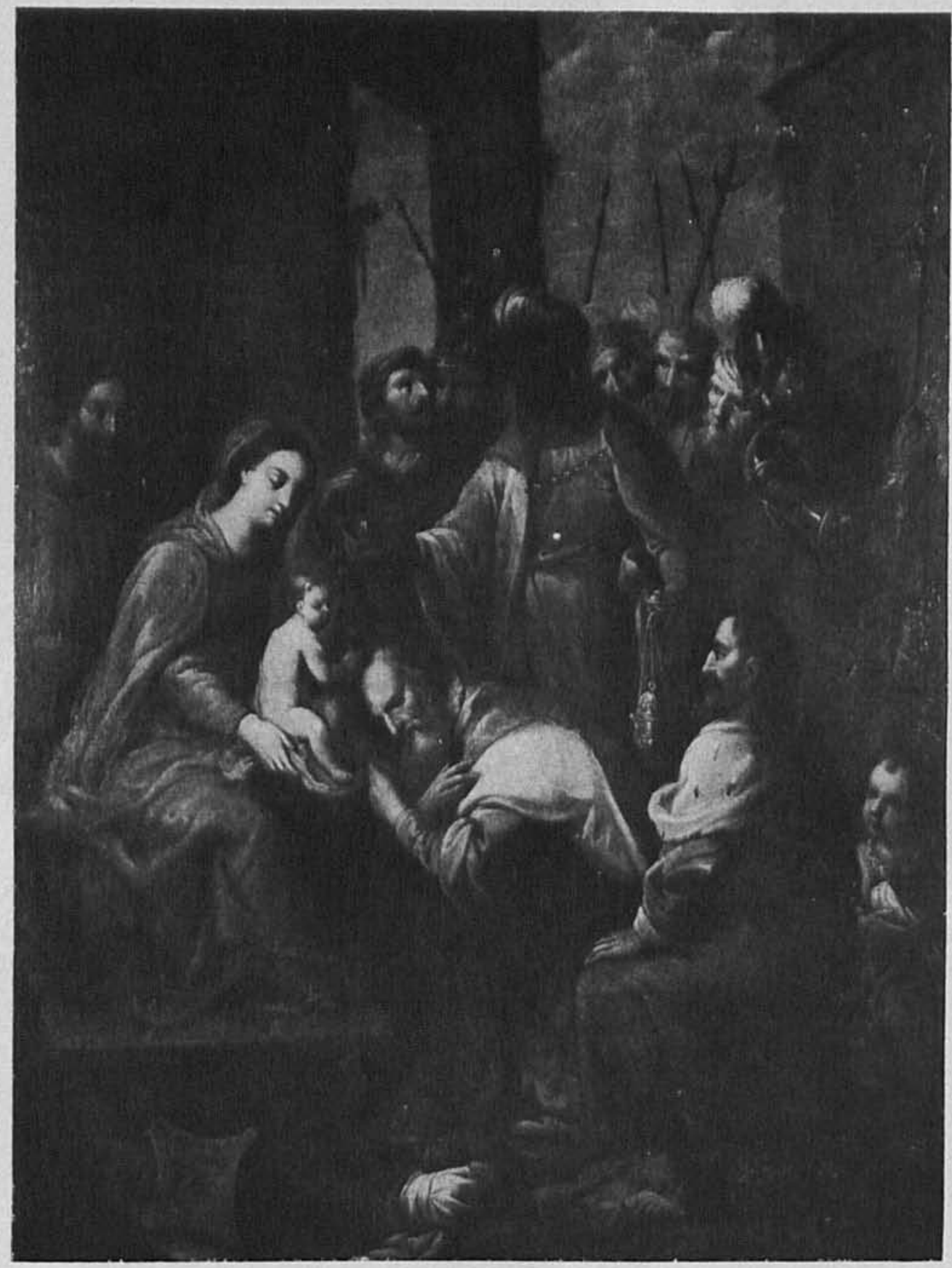

2. Miguel Cabrera: La Adoración de los Reyes, Museo de América, Madrid, España 
el Soneto q. hizo a la Esperanza y se copia arriba). Murió con Religiosisimas exemplares demostraciones de Catholica y Religiosa, manifestando el Acierto mayor de su elevado Ingenio en saber morir; a las 4 de la mañana del dia 17 de avril de el año 1695 haviendo vivido 44 años, 5 meses, 5 días y 5 horas.

Soneto a la esperanza

Verde embeleso de la vida humana

loca esperanza frenesi dorado, sueño de los despiertos intrincado como de sueños, de tesoros vana; Ahora del mundo, Senectud lozana, decrépito verdor innaginado, El hoy de los dichosos, superado, $Y$ de los desdichados, el mañana; Ligan tu sombra en vusca de tu día, los que de verdes vidrios por Anteojos todo lo ven pintado a su deseo;

Que yo, mas cuercla en la fortuna mia tengo en entrambas manos ambos ojos. Y solamente lo que toco veo.

Con esto doy por terminada esta breve aportación sobre el prolífico pintor Miguel Cabrera, viniendo a completar las noticias suministradas sobre vida y obras por Toussaint en su mencionado libro.*

- Agradezco a la dirección del Museo de América las facilidades concedidas para hacer este trabajo. 